This work is licensed under a Creative Commons Attribution-NonCommercialNoDerivs 3.0 Licence.

To view a copy of the licence please see: http://creativecommons.Org/iicenses/by-nc-nd/3.0/ 


\section{INSTITUTE \\ FOR \\ DEVELOPMENT STUDIES \\ UNIVERSITY COLLEGE, NAIROBI}

THE USE OF SAMPLE HOUSEHOLD EXPENDITURE SURVEYS IN ECONOMIC PLANNING IN EAST AFRICA

by

Charles W. Howe

Resources for the Future, Inc.

Washington, D. C.

Reprint No. I9

Reprinted for private circulation from the

Bulletin of the Oxford University Instiute

of Economics \& Statistics, Volume 28, No. 3, 1966

with the permission of the Editors.

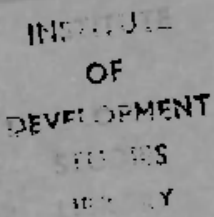




\section{REPRINTS}

*1. P. Robson: Stagnation or Growth for East Africa?

*2. D. M. Etherington: Land Settlement in Kenya; Policy and Practice.

*3. D. A. Lury: National Accounts in Africa.

*4. J. E. Price: International Burden-Sharing.

*5. C. W. Howe \& H. Karani: A Projection Model for the Kenya Economy.

6. D. M. Etherington: Projected Changes in Urban and Rural Population in Kenya and the Implication for Development Policy.

7. M. Gaskin: Monetary Flexibility in Dependent Economies.

8. C. A. Cooper and B. F. Massell: Toward a General Theory of Customs Unions for Developing Countries.

9. P. Robson: The Problem of Senegambia.

10. C. A. Cooper and B. F. Massell : A New Look at Customs Union Theory.

11. J. H. Proctor: The Role of the Senate in the Kenya Political System.

12. J. H. Proctor and K. G. V. Krishna: The East African Common Services Organization: An Assessment.

13. D. A. Lury: The Trade Statistics of the Countries of East Africa 1945-1964 and African Population Estimates: Back Projections of Recent Census Results.

*14. J. H. Proctor, Jr.: The Effort to Federate East Africa: A PostMortcm.

15. D. A. Lury \& A. A. Shah: Local Government in Kenva: Income and Expenditure 1959-1961.

16. William Barber: Some Questions about Labour Force Analysis in Agrarian Economies with Particular Reference to Kenya.

17. J. Heyer: Kenya's Cautious Development Plan.

18. J. Heyer: Kenya's Agricultural Development Policy.

19. C. W. Howe: The Use of Sample Household Expenditure Surveys in Economic Planning in East Altica

«No longer available.

Book

Number 


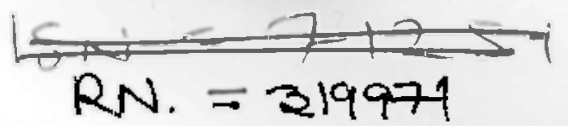

\title{
'THE USE OF SAMPLE HOUSEHOLD EXPENDITURE SURVEYS IN ECONOMIC PLANNING IN EAST AFRICA'1
}

\author{
By Charles W. Howe
}

\section{INTRODUCTION}

The basic point of this paper is that sample surveys, particularly household expenditure surveys, provide an efficient, low-cost method of predicting aggregate final consumption demands during periods of rapid structural change in a developing economy. In fact, it is likely that the analysis of sample household surveys is the only basis on which reasonably accurate predictions of final consumer demand can be made. At present in East Africa, no use is being made of this approach, and the few surveys that are being carried out are intended primarily to provide the weights for price indices or to give indications of the general level of living of various wage-earning groups. Such surveys usually are not appropriately designed to provide all the information desirable for predicting changes in consumer demand as incomes rise, but they could easily be amended in the future to fulfill this valuable objective.

The expenditure side of the national accounts is very incomplete in East Africa. Collecting additional detail will be expensive, coverage will not be uniform over different sections of the country and different groups, and, even if such a programme is started soon, it will require several years befure reliable aggregate time series on expenditures are available. There are, however, serious objections to using aggregate time series data even when available as the basis for demand predictions, the most serious of which is that income is being and will be redistributed extensively among sub-groups of the population whose consumption behaviour differs tremendously, Many of these inter-group differences in behaviour are not explainable in terms of income alone. Thus part of the economic 'structure' is changing, making historical aggregate time series data on expenditures misleading as a basis for making predictions of the future.

What is needed in the East African countries is a well planned, co-ordinated series of household surveys covering the major consumer groups (racial, tribal, geographical) which can be expected to exhibit different patterns of expenditure relative to income.

It must be remembered that the future demands which planners must predict are those which will be expressed through the market and which presently or in the future will require a specialization of function in the agricultural sector, further development of marketing arrangements, increased manufacturing capacity, expanded imports or expansion of transport capacity. Demands which will be satisfied through home production (on the family farm or 'shamba') need not be extrapolated in detail for planning purposes, but, since the amount

1 The author wishes to acknowledge the useful comments and suggestions of Mr. Dennis Lury of University College, Nairobi and Mr. J. B. Knight of Oxford University Institute of Economics and Statistics. 
of home production will affect the pattern of market expenditures, different patterns of expenditure can be expected among groups whose capacities for home production differ. These capacities are, in part, a function of the size of the urban area in which the household is located (in Nairobi, a smaller proportion of industrial or government workers will be able to live far enough from town to have large gardens or 'shambas' than would be the case in Kampala or Gulu), the climatic factors and soil conditions which determine the returns to 'shamba' labour when land is available, and even the occupation of the head of household (domestics' hours allow little time for gardening, while many white collar workers would consider such work beneath their dignity).

Other factors which lead to an a priori expectation of inter-group differences in expenditure patterns are religious dietary restrictions, habits instilled by the local availability or non-availability of particular products (the availability of fish in the lake regions or the lack of fresh vegetables in arid areas), and climate which affects clothing and housing requirements.

Different surveys would thus have to be carried out among sub-groups of the population differing in the characteristics mentioned above so that the demand functions appropriate to each group could be estimated. Of course, the results may indicate that some of these groups do not differ significantly in behaviour. This, however, must be empirically demonstrated and not assumed.

These surveys could be quickly and relatively inexpensively carried out because of their very specific objectives. Not all commodities and services consumed by the household need be covered by the surveys. Goods could be omitted which are now being produced in adequate quantities close to the markets in which they are sold, for which adequate marketing arrangements and transport facilities are now available, and for which production could be expanded without displacing other activities. Plantains and ground nuts are examples of quantitatively important crops which, because of the localization of production and marketing and the ease of expanding output through traditional methods of cultivation, might not need to be included in the surveys.

Criteria for the inclusion of a commodity in the surveys should include:

1. that increased demand for the good require expanded inter-regional trade and thereby increased transport capacity and new marketing arrangements (e.g. dairy products produced in the Kenya highlands);

2. that substantial time lags be involved in increasing output (e.g. building up cattle herds for provision of beef);

3. that substantial investment or foreign exchange be required to increase supplies (e.g. the provision of motor vehicles either through local production or imports).

It might be hoped that the results of demand studies carried out in other underdeveloped areas could be applied to East Africa, or carried over from one East African country to another. The available evidence indicates that this would be a risky undertaking. Houthakker, in a very interesting article (13), found wide ranges of income elasticities for the sixty-four countries, regions and time periods covered: total food .344 to .731; clothing and footwear .918 to 1.784; housing (including fuel and light but not furniture) .346 to 1.114; all other 
items 1.081 to 1.879 . These elasticities were estimated as coefficients of doublelogarithmic functions relating expenditures on the indicated commodity group to total expenditure of the household. Correction was made for household size by including number of persons as a variable in the function for those cases where the surveys provided the appropriate cross-classifications. Estimated elasticities did not vary in a regular way with general level of income, and substantial variations were found among those countries which might be classified as 'under-developed'. Examples of elasticities found for 'total food' are: Brazil .795, Burma .826, Ceylon .810, China .591, Cuba .704, Ghana .840, Guatemala .508, India .709, Libya .805, Philippines .757, and Northern Rhodesia (Zambia) .393. While relative prices may have accounted for some of these differences, it must be remembered that categories such as 'total food' are gross aggregations, so that elasticities for more narrowly defined categories may well exhibit even wider ranges of variation. Houthakker concludes with respect to development planning:

'If no data on the expenditure patterns of a country are available at all, one would not be very far astray by putting the partial elasticity with respect to total expenditure at 0.6 for food, 1.2 for clothing, 0.8 for housing, and 1.6 for all other items combined. ... But it would be prudent not to use these guesses for wide extrapolations, and more prudent still to organize a survey and cross-classify the results'

Further evidence is available for East Africa. Marion Forrester (11) found strong tribal differences in expenditure patterns. The present author also has developed evidence on this point. Table 1 presents percentages of income spent and cash income elasticities for Nairobi, Kampala, and for combined observations from Mbale, Fort Portal, and Gulu. The Nairobi data were taken from lower and middle income African household surveys $(6,16)$ with income and expenditure being deflated by the number of adult equivalents according to the scale: children less than 16 years $=0.6$, females 16 years and older $=0.8$, and males over 16 years $=1.0$. Nairobi represents the African household in the truly urban setting. Kampala data $(5,7)$ represent an intermediate setting of the African worker who works at a city job but frequently lives where some home produce can be grown. Unfortunately, the Kampala surveys contained no information on the quantities or value of home produce nor on average household size. The household surveys in Mbale, Fort Portal, and Gulu represented African workers holding unskilled jobs in town but living on 'shambas' which produced substantial portions of the households' food requirements and frequently contributed to cash income (e.g. sale of cotton). These data were deflated by average household size and expenditures were expressed as functions of both cash income and value of 'shamba' produce consumed by the household. It was thus possible to obtain elasticities both with respect to cash income and value of home produce consumed.

Various functional forms were used in estimating the elasticities of Table 1 , none being linear except for 'total expenditure'. Most of the functions were semi-logarithmic in form, so that the elasticities change with income levels. Thus the different elasticities need not imply different behaviour patterns but 
TABLE 1

Comparison of African Household Expenditure Pallerns ${ }^{1}$

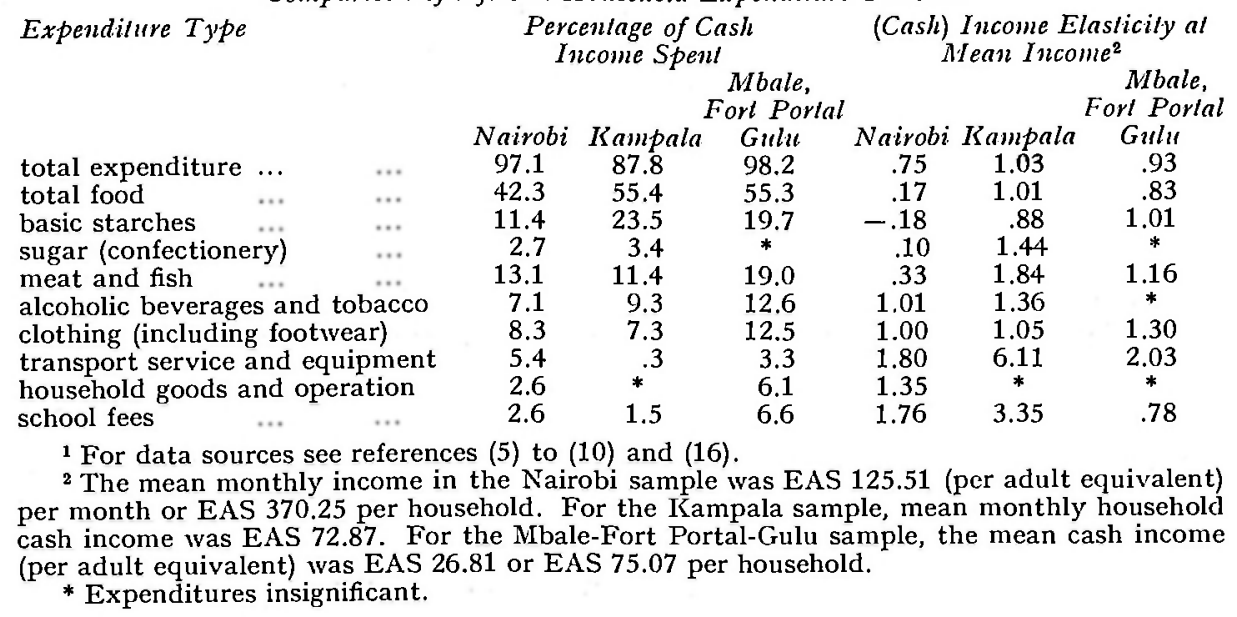

might simply reflect different mean income levels for the households surveyed. This, however, was not the case, for the parameters of the fitted Engel curves were significantly different (Howe, 15). Table 2 presents values of cash income elasticities for Mbale, Fort Portal, and Gulu obtained by using the Engel curves fitted to the data from those areas and then advancing average cash incomes to Nairobi levels. The implied elasticities differ substantially from the actual Nairobi elasticities, an indication of the errors which could be committed either by applying the results of analysis of one population sub-group to the prediction of expenditures in other areas or by using a given set of relationships (the Mbale-Fort Portal-Gulu functions) to extrapolate over such a wide range of incomes (EAS 75/07 per household per month for Mbale-Fort Portal-Gulu versus EAS 370/25 per household per month for Nairobi).

\section{The Use of Sample Expenditure Surveys}

It is unnecessary to comment upon the general principles involved in sampling techniques, for excellent treatises are available on the subject. Sampling (as opposed to complete enumeration) permits cost reductions and, frequently, increased accuracy because of the attention which can be given to obtaining accurate answers from respondents. In studying expenditure patterns, it is generally agreed [see (14)] that the household is the relevant decision-making unit and, therefore, the unit from which data should be gathered. To insure observation of a sufficient range of variation of the characteristics of the households, the sample is usually stratified by income and, preferably, by household size. On the basis of the data so gathered, it is then possible to make point or interval estimates of population parameters of interest such as the mean household income, mean levels of expenditures on different commodities, etc.

These points estimates are not, however, what is needed for planning purposes. While it is of interest to know the characteristics of the population of households today, what is needed is a system of relationships which will permit 
TABLE 2

A Comparason of Income Elasticities of Demand Evaluated at Nairobi Income Levels

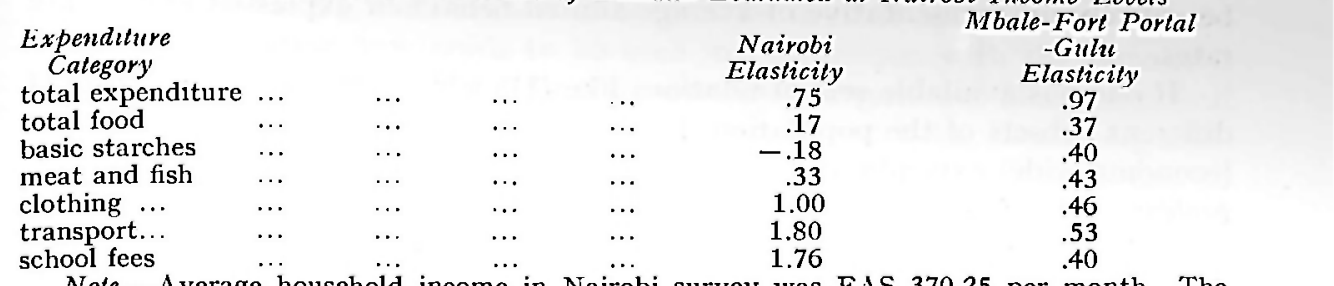

Note.-Average household income in Nairobi survey was EAS 370.25 per month. The average for the Mbale-Fort Portal-Gulu surveys was EAS 75.07 per month cash or EAS 109.73 per month including value of home produce consumed.

prediction of the changes in economic behaviour of the households as economic development takes place. Of particular importance will be predictions of expenditures and saving as household incomes rise.

The ideal approach to making these predictions would be to estimate statistically from the survey data household demand functions of the general form

(1) $\mathrm{q}_{\mathrm{ij}}=\mathrm{f}\left(\mathrm{x}_{\mathrm{j}}, \mathrm{P}_{\mathrm{i}}, \mathrm{n}_{\mathrm{j}}\right)$

where $q_{i j}$ is the quantity of the ith commodity demanded by the $j$ th household whose money income is $x_{j}$, with $n_{j}$ members of the household, and $p_{i}$ is the price of the particular commodity. It would be desirable to introduce relative prices into the demand function, for relative prices may change during periods of rapid development. However, it is doubtful that sufficient variation in relative prices could be observed within the surveyed groups to make such inclusion empirically possible. Sets of such demand functions for the important consumer commodities would permit predictions to be made of the quantities demanded by households of different population sub-groups, using various assumptions about incomes $\left(\mathrm{x}_{\mathrm{j}}\right)$ and prices $\left(\mathrm{p}_{\mathrm{j}}\right)$ in accordance with changes anticipated during the development planning period. There exist procedures (to be discussed below) for aggregating the household demand functions to get aggregate demand functions.

This ideal approach usually has to be compromised for lack of data on quantities and prices. Future surveys may be able to provide these data, but it is usually easier to keep records of expenditure than of quantities, and prices are frequently difficult to define where markets are quite imperfect and often characterized by bargaining. The compromise usually takes the form of fitting Engel curves, that is relating expenditures on a commodity to household income and household size. The general form is

(2) $y_{i j}=g\left(x_{j}, n_{j}\right)$

where $y_{1 j}$ is the expenditure of the $\mathrm{jth}$ household on the ith commodity.

Since there are several possible ways of defining household income (before or after tax, with or without the value of certain employment perquisites, with or without the value of home grown goods consumed), total expenditure is frequently substituted for income. When incomes are low and savings nil, the differences are negligible, perhaps with the exception of cases where housing is provided as a condition of employment. Surveys, however, must be planned to cover sufficiently long periods of time to allow representative average expenditures and income to be computed. For example, incomes and expenditures 
observed during months of cotton sales in Uganda or coffee sales in Kenya would be entirely unrepresentative of average annual behaviour expressed in monthly rates.

If one has available sets of relations like (11) which represent households of different subsets of the population, how is it possible to get predictions of total (economy-wide) expenditures? This is one form of the oft-discussed aggregation problem. As discussed earlier, there will be population sub-groups whose expenditure behaviour must be expected to be quite different. The East and Central African countries, for example, still have large and economically important European populations, substantial Asian and Middle-Eastern groups, and large numbers of tribally and geographically differentiated African groups. Planning will require separate sets of relations like (11) for at least some of these groups. Just how many groups must be differentiated for these purposes can be resolved only through empirical investigation. The procedures that follow will then apply to each sub-group.

To predict the total demand for a particular commodity by some population sub-group, it would suffice, by definition, to know the appropriate mean expenditure per household on that commodity for that sub-group. That is

(3) $\tilde{Y}=N \cdot y$

where $\mathrm{N}$ is the number of households in the sub-group and $\mathrm{y}$ is the mean expenditure per household on the commodity in question. The projection needed for planning purposes, however, refers to some future point in time when household incomes and possibly household sizes will have changed substantially from present levels. Present values of y are of no use. It is at this point that Engel curves estimated from sample survey data become useful.

First, let us consider what information is likely to be available regarding future characteristics of the sub-group whose behaviour we are trying to project. Hopefully, estimates will be available of the number of households, average income levels, and average household sizes. Such estimates can at times be found explicitly stated in national economic plans, or can be derived from demographic projections based on census data. Accurate forecasting of household demands will, as we will see below, require even more information, namely a knowledge of the joint frequency distribution of households by income levels and household sizes. Such a joint distribution can most easily be thought of in the form of a table:

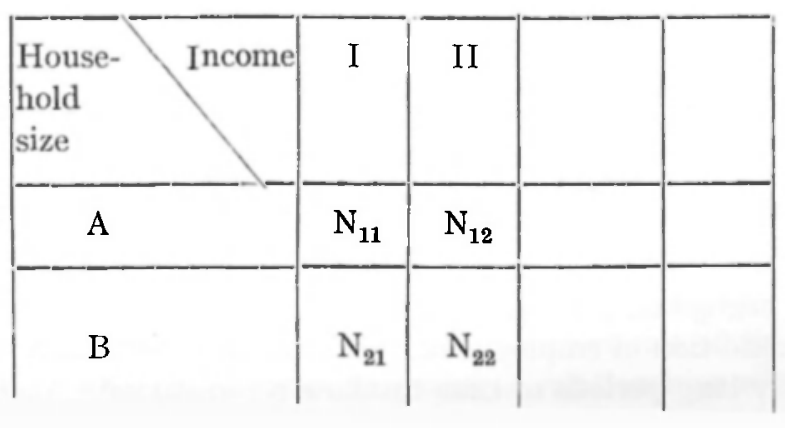


where the numerals indicate income intervals, letters indicate household-size intervals, and the $\mathrm{N}_{\mathrm{kl}}$ the numbers of households in each cell.

This information now needs to be used in conjunction with the estimated Engel curve to get total demand for the commodity in question. Much empirical evidence $(2,12,13,14,15,17)$ indicates that semi-logarithmic, double-logarithmic, and other non-linear functional forms constitute appropriate models of household consumption behaviour. The practical consequence of non-linear Engel curves is that the mean household expenditure usually cannot be estimated directly from a knowledge of mean household income and size. That is

(4) $y \neq g(x, n)$

unless $g$ is linear or unless all households are of the same size and income, i.e. unless there is no dispersion of $x$ 's and n's about their means. The degree of error involved in estimating y by $g(x, n)$ decreases as the dispersion of $x$ 's and $n$ 's decreases. This suggests partitioning the households into income-household cells as exhibited in the preceding table, so that the amount of intra-cell variation is small. Then the mean household expenditure for each cell can be approximated by

(5) $\mathrm{y}_{\mathrm{kl}} \approx \mathrm{g}\left(\mathrm{x}_{\mathrm{k} \mathrm{k}}, \mathrm{n}_{\mathrm{kl}}\right)$

the degree of approximation being closer the more finely the population is subdivided. Total expenditure for each cell is then approximated by

(6) $\tilde{\mathrm{Y}}_{\mathrm{kl}} \approx \mathrm{N}_{\mathrm{kl}} \cdot \mathrm{g}\left(\mathrm{x}_{\mathrm{kl}}, \mathrm{n}_{\mathrm{kl}}\right)$

Summing over the cell totals then yields the estimate of aggregate expenditure for the population sub-group in question.

For certain special cases there are aesthetically more pleasing and more accurate ways of proceeding from the Engel curve to predictions of aggregate demand. One of these special cases which may quite well approximate actual conditions for some commodities and populations is that in which it is assumed that:

(a) the Engel curve in (11) has the semi-logarithmic form

$$
\mathrm{y}=\beta_{0}+\beta_{1} \log \mathrm{x}+\beta_{2} \log \mathrm{n}
$$

(b) household income and household size have a joint log-normal frequency distribution (i.e. their logs are normally distributed) with parameters

$$
\sigma_{\log x}, \sigma_{\log \mathrm{n}} \text {, and } \rho_{\log \mathrm{x}, \log \mathrm{n}}
$$

It should be noted that the semi-logarithmic form in income has been found applicable particularly to foodstuffs, rent, and entertainment. [14, Chapter 7] and that for foodstuffs it is also likely that certain economies of scale come into play as household size increases. Such a phenomenon is represented by the semi-logarithmic form in n. Once the Engel curve has been estimated, the following relationship permits the estimation of household arithmetic mean expenditure from estimated or predicted future values of mean household income and size (see the Appendix for derivation):

(7) $\bar{y}=\bar{\beta}_{0}+\beta_{1}\left(\log x-\frac{1}{2} \sigma_{\log x}^{2}\right)+\beta_{2}\left(\log \bar{n}-\frac{1}{2} \sigma_{\log n}^{2}\right)$

The variances may be estimated from the same current survey data used in estimating the Engel curve, or they may represent expected future conditions. Knowing $\mathrm{y}$ and the number of households in the population sub-group then 
permits computation of the estimate of aggregate expenditure, $\widetilde{Y}=N \bar{y}$.

Another useful special case is that in which it is assumed that:

(a) the Engel curve in (11) has the form (linear in logs):

$$
\mathrm{y}=\beta_{0} \mathrm{x}^{\beta 1} \mathrm{n}^{\beta 2} \text {; }
$$

(b) household income and household size have a joint log-normal frequency distribution (i.e. their logs are normally distributed) with parameters

$$
\sigma_{\log x}, \sigma_{\log n} \text {, and } \rho_{\log \mathrm{x}, \log \mathrm{n}}
$$

The double logarithmic form has been found applicable particularly to consumer durables, clothing (over limited income ranges), and fuel and light (14, Chapter 7, and 13]. The following somewhat more complicated expression permits estimation of arithmetic mean expenditure from estimated or future values of average household income and size (see the Appendix for derivation):

(8) $\log \mathrm{y}=\log \beta_{0}+\beta_{1} \log \mathrm{x}+\beta_{2} \log \mathrm{n}$

$$
\begin{aligned}
& +\left(\frac{1}{2}\right)\left(\beta_{1}^{2}-\beta_{1}\right) \sigma_{\log x}^{2}+\left(\frac{1}{2}\right)\left(\beta_{2}^{2}-\beta_{2}\right) \sigma^{2}{ }^{2} n \\
& \mid \beta_{1} \beta_{2} \rho_{\log x}^{\sigma} \cdot{ }^{\sigma} \log n .
\end{aligned}
$$

The same procedures as suggested above can be followed.

\section{Shortcomings of the Engel Curve Approach}

The Engel curve represents a more basic or elemental economic relationship than an aggregate consumption or expenditure function. It thus appears likely that this relationship will be more stable over time than the more aggregative functions. However, tastes do change in the course of economic development, particularly as the variety of available goods and level of education increase. New surveys will thus be required periodically as development progresses.

Another weakness in the approach is the omission of relative prices from the analysis. While it may be difficult to observe a sufficiently wide range of price variation in a cross-section survey, more attention should be paid to obtaining price data in future surveys.

It may be that long term income elasticities will differ from those indicated by cross-section surveys. Duesenberry's relative income hypothesis indicates that rising general levels of income and expenditure will induce higher levels of household expenditure than would occur if only one household in an unchanged environment experienced higher income.

Some evidence on this point has already been introduced in Table 2. Cash income appropriate to Nairobi was introduced into the Engel curves estimated for Mbale-Fort Portal-Gulu and the elasticities were evaluated at that point. The result appears to be an overstatement of elasticities for those commodities which might be considered necessities (food, starches, and possibly meat and fish) and an understatement of elasticities for 'luxuries' (clothing, transport and school fees). While this evidence is not conclusive because of the tribal and climatic differences between the areas, it suggests the cautionary note that a given estimated function is likely to provide a good approximation to the actual expenditure-income relationship only over a limited income range. For a given population sub-group, new surveys will have to be taken more frequently in areas of rapid income change (say, every four to five years if household incomes grow at six per cent) than in slower growing areas (about every eight years at a three per cent rate). 
Another shortcoming shared by all approaches relying on expenditure data is that expenditure is the product of quantity and price. If markets are competitive, price can be taken as a measure of quality. Thus as we observe increasing expenditures with rising incomes, the increase is compounded of an increased demand for quantity and a demand for improved quality. The latter effect can be substantial [(14, Chapter 8), (3), (4)] especially for meat and fish and other commodities which are typically available in the market in a variety of qualities. Separate studies of quality elasticities using methods such as those referred to in the above references can provide factors of conversion to permit predictions of quantity (as opposed to expenditure) to be made from Engel curves. Such studies may not prove feasible because of the increased demands they place on accurate data collection. The lack of proportionality between quantity and expenditure can, however, be reduced by using more narrowly defined commodity categories.

\section{Conclusions}

Household survey techniques, utilizing the estimation of Engel curves for important categories of consumer expenditure, hold much promise for use in economic planning in East Africa. Aggregate time series data on consumption simply are not available, and necessary estimates of future demands are being made on the basis of sketchy and inappropriate data. The Engel curve approach permits the prediction of aggregate consumer demands for commodities in the absence of historical time series and permits an explicit analysis of the impact on expenditures of

1. changing income distribution within important population sub-groups;

2. changing income distribution among population sub-groups;

3. a changing distribution of household sizes;

4. the growth of income over time.

Since sample surveys, when well planned, can be fairly inexpensively carried out (particularly if a well trained survey unit is maintained intact for such purposes), the application of these techniques should permit East African countries to overcome the formidable difficulties now faced of predicting consumer demands during periods of rapid economic and social change.

\section{APPENDIX}

The Derivation of Aggregate Expenditure Functions from Santple Surveys

A. The Semi-logarithmic Case

Assume that the Engel curve for all households in the population sub-group has the form

(A1) $\mathrm{y}=\beta_{0}+\beta_{1} \log \mathrm{x}+\beta_{2} \log \mathrm{n}$.

Summing over all households and dividing by the number of households, one gets

(A2) $\bar{y}-P_{0}: o_{1}\left\{\frac{\sum \log x_{1}}{\mathrm{~N}}\right\}+\rho_{2}\left\{\frac{\Sigma \log n_{1}}{\mathrm{~N}}\right\}$

or, letting $\mathrm{x}^{*}$ and $\mathrm{n} *$ represent the geometric means,

(A3) $\mathrm{y}=\beta_{0}+\beta_{1} \log \mathrm{x}^{*}+\beta_{2} \log \mathrm{n} *$ 
Any log-normal variate [see 4], as $\mathrm{x}$ is assumed to be, has the property that (A4) $\log \mathrm{x}^{*}=\log \mathrm{x}-\frac{1}{2} \cup_{\log } \mathrm{x}$.

Substituting this relationship for $x^{*}$ and $n^{*}$ in (A3) yields the result

(A5) $y=\beta_{0}+\beta_{1}\left(\log x-\frac{1}{2} \sigma_{\log x}^{2}\right)+\beta_{2}\left(\bar{n}-\frac{1}{2} \sigma_{\log n}^{2}\right)$.

B. The Double-logarithmic Case

Assume that the Engel curve for all households in a population sub-group has the form

(A6) $y=\beta_{0} x^{\beta_{1}}{ }^{\beta_{2}}$

with the same values $\beta_{0}, \beta_{1}$, and $\beta_{2}$ for all households.

Taking logs and summing over all households in the population sub-group

(A7) $\Sigma \log \mathrm{y}_{\mathrm{i}}=\mathrm{N} \log \beta_{0}+\beta_{1} \Sigma \log \mathrm{x}_{\mathrm{i}}+\beta_{2} \Sigma \log \mathrm{n}_{\mathrm{i}}$

Taking anti-logs and $N$ th roots:

(A8) $\left(\pi y_{i}\right)^{1 / N}=\beta_{0}\left[\left(\pi x_{i}\right)^{1 / N}\right]^{\beta_{1}}\left[\left(\pi n_{j}\right)^{1 / N}\right]^{\beta_{2}}$

This is a relationship between the geometric means of expenditure, income, and household size, statistics which are not generally available from survey sources. If we let $\left(^{*}\right)$ variables represent geometric means, taking logs of (A8) yields

(A9) $\log \mathrm{y}^{*}=\log \beta_{0}+\beta_{1} \log \mathrm{x}^{*}+\beta_{2} \log \mathrm{n}^{*}$.

For any log-normal variate (see [4]) like $\mathrm{x}$, it is the case that

(A10) $\log x^{*}=\log x-\left(\frac{1}{2}\right) \sigma_{\log x}^{2}$.

The simple rules of distribution theory also permit us to derive from the log form of (A6) that

(All) $\sigma_{\log y}^{2}=\beta_{1}^{2} \sigma_{\log x}^{2}+\beta_{2}^{2} \tau_{\log n}^{2}-2 \beta_{1} \beta_{2} \rho \sigma \log x{ }^{\sigma} \log n$.

Making the type of substitution (A10) for $\log y^{*}, \log x^{*}$, and $\log n^{*}$ in (A9) and then applying (All) yields the result

(A12) $\log \mathrm{y}=\log \beta_{0}+\beta_{1} \log \mathrm{x}+\beta_{2} \log \mathrm{n}$

$+\left(\frac{1}{2}\right)\left(\beta_{1}^{2}-\beta_{1}\right) \sigma_{\log x}^{2}+\left(\frac{1}{2}\right)\left(\beta_{2}^{2}-\beta_{2}\right) \mathrm{c}_{\log n}^{2}$

$+\beta_{1} \beta_{2}{ }^{\circ} \log \mathrm{x}^{\prime 5} \log \mathrm{n}$.

Washington, D.C.

\section{REFERENCES}

(1) Aitcheson and Brown, The Log-Normal Distribution. North Holland Press.

(2) Bennett, Merrill K., The World's Food, New York, 1954.

(3) Black, G.:'Variations in Prices Paid for Food by Income Level', Joumnal of Farm Economics, XXXIV (1952), 0p. 52.

(4) Bristol, R.: Unpublished Ph.D. Thesis, Yale, 1955.

(5) East African Statistical Department: 'Thè Patterns of Incomè, Expenditure, and Consumption of African Unskilled Laborers in Kampala, September, 1953' (1954).

(6) East African Statistics Department (Kenya Unit): 'Patterns of Income, Expenditure, and Consumption of Africans in Nairobi, 1957/58' (1959).

(7) East African Statistical Department (Uganda Unit): 'Patterns of Income, Expenditure, and Consumption of African Unskilled Workers in Kampala, February, 1957.' (1957). 
(8) East African Statistical Department (Uganda Unit): 'The Patterns of Income, Expenditure, and Consumption of African Unskilled Workers in Mbale, February 1958.' (1958).

(9) East African Statistical Department (Uganda Unit): 'The Patterns of Income, Expenditure, and Consumption of African Unskilled Workers in Gulu, February, 1959.' (1959).

(10) East African Statistical Department (Uganda Unit): 'The Patterns of Income, Expenditure, and Consumption of African Unskilled Workers in Fort Portal, February, 1960.' (1960).

(11) Forrester, Marion: Kenya Today: Social Prerequisites for Economic Development. International Institute for Social Studies: The Hague, 1962, p. 123.

(12) Goreux, L. M., 'Revenu et Consommation Alimentaire', Bulletin MensuelEconomic et Statistique Agricoles, Vol. IX, No. 10, Octobre, 1960.

(13) Houthakker, H. S.: 'An International Comparison of Household Expenditure Patterns, Commemorating the Centenary of Engel's Law', Econometrica (1957), pp. 532/551.

(14) Houthakker, H. S. and S. J. Prais: The Analysis of Family Budgets. Cambridge (England): 1955. Chapters 2 and 3.

(15) Howe, C. W., 'The Use of Sample Household Surveys in Economic Planning with Some Empirical Results for East Africa', 'Center for Economic Research Discussion Paper No. 12, July, 1965, University College, Nairobi.

(16) Kenya Government, Ministry of Finance and Economic Planning: 'The Patterns of Income, Expenditure, and Consumption of African Middle Income Workers in Nairobi, July, 1963'. (1964).

(17) Wold, H. and L. Jureen, Demand Analysis, New York, 1953. 


\section{OCCASIONAL PAPERS}

1. J. Heyer: The Economics of Small-Scale Farming in Lowland Machakos.

Supplement to No. 1.: Input-Output Data from 16 Smallholdings in Masii Location, Machakos District, 1962/3.

2. B. F. Massell and J. Heyer: Household Expenditure in Nairobi: A Statistical Analysis of Consumer Behaviour.

Publications may be obtained from:

The Secretary,

The Institute for Development Studies,

University College, Nairobi,

P.O. Box 30197,

Nairobi. 